\title{
New methods of preservation of the ovarian reserve during operations on the ovary, Individual tactics. A simple solution (preliminary report)
}

\author{
VG Zhegulovych*1 and Yu V Zhegulovych ${ }^{2}$ \\ ${ }^{1}$ OO Bogomolets National Medical University, Ukraine \\ ${ }^{2}$ Kiev City Clinical Hospital \#18, Ukraine
}

Received: 眥April 15, 2018; Published: 眥 April 23, 2018

*Corresponding author: VG Zhegulovych, 00 Bogomolets National Medical University, Kiev, Ukraine

\section{Short Communication}

Currently, surgical treatment of the ovaries is carried out mainly by laparoscopic entry. Surgical interventions are always associated with the need for hemostasis. All types of energy that are used in surgery (mechanical, electrical, thermal, welding, laser, etc.), depending on various pathophysiological mechanisms, affect the ovarian tissue and damage the ovarian reserve in women of reproductive age $[1,2]$. The ovarian suture causes an intense inflammatory reaction to the foreign body (tissue necrosis, granulation tissue) even around the suture material that dissolves within 30-60 days. In surgery, conservative hemostasis methods involving temporary compression are widely used: hemostasis during acute gastroduodenal ulcer bleeding, liver damage.

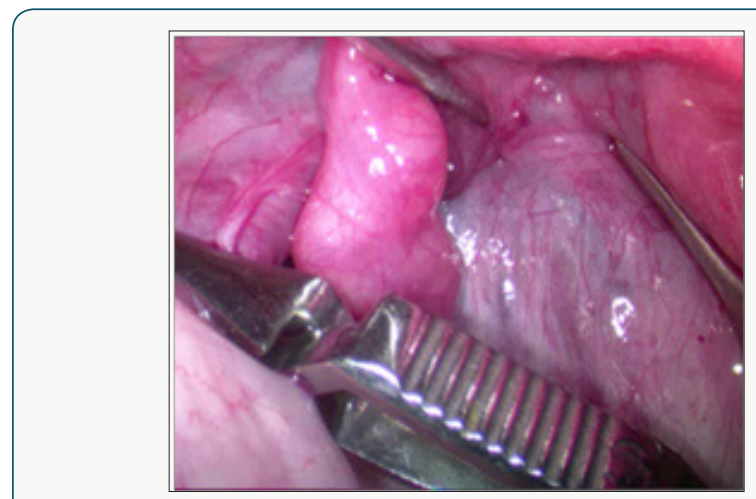

Figure 1: Vascular bulldog clamp on the ligaments.

Thus, temporary compression hemostasis can be suggested as an alternative to thermal and ultrasound methods and as the one that causes minimal damage to the ovarian reserve. Furthermore, phylogenetically the ovary "got used" to permanent monthly hemorrhages, hematomas and ischemia during ovulation. Taking into account the peculiarities of ovarian blood supply, as well as natural monthly traumatization of the ovaries accompanied by the formation of hematomas in the area of an ovulation stigma, it was decided to use temporary compression of the ovarian tissue to achieve hemostasis $[3,4]$. Tactics of the removal of endometrioid and dermoid ovarian cysts includes the following sequential steps:

a. Placement of the vascular bulldog clamps on lig infundibulopelvicum and lig. ovarii proprium (Figure 1).

b. Introduction of several drops of the vasopressor (adrenaline, vasopressin) into the mesosalpinx and mesovarium [5].

c. Removal of the cyst capsule from the ovarian tissue (with minimal capillary hemorrhage and without coagulation) (Figure 2).

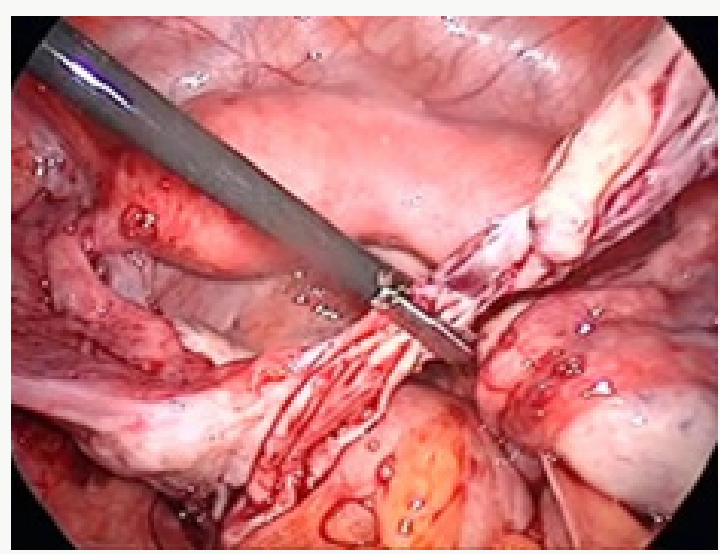

Figure 2: Separation of the cyst capsule.

d. Ovarian suture and tethering of the ovary to the abdominal wall by straight needle with the monofilament thread (ventrosuspension) (Figure 3).

e. Removal of the vascular bulldog clamps.

f. Assessment of hemostasis and chromohydrotubation. 

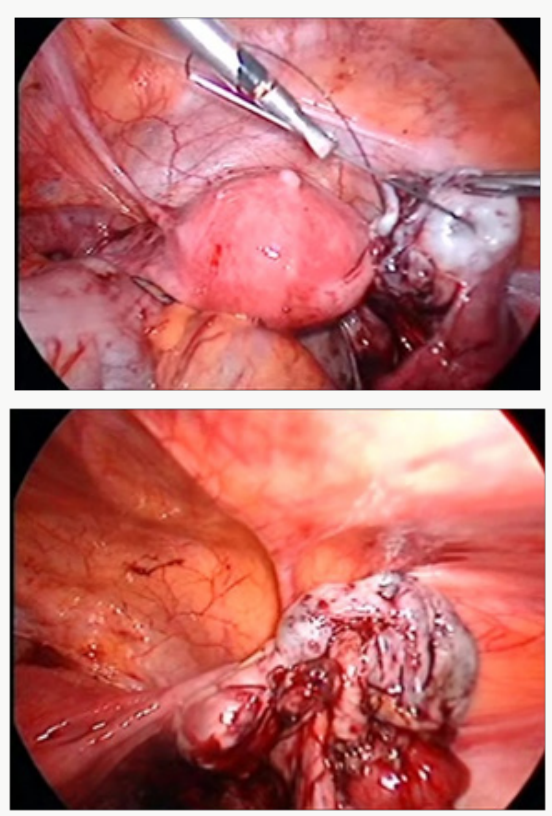

Figure 3: Ovarian suturing and temporary ventrosuspension.

During surgical treatment of the ovaries affected by thin-walled structures (follicular cysts, corpus luteal cysts, simple serous cystadenomas), stitching of the thinned ovarian tissue with the monofilament thread may appear ineffective. The thread cuts through. Therefore, it is advisable to use the Foley catheter No. 6 or No. 8 for temporary ovarian ventrosuspension. A soft inflated rubber balloon effectively presses the ovary to the abdominal wall (Figure 4).
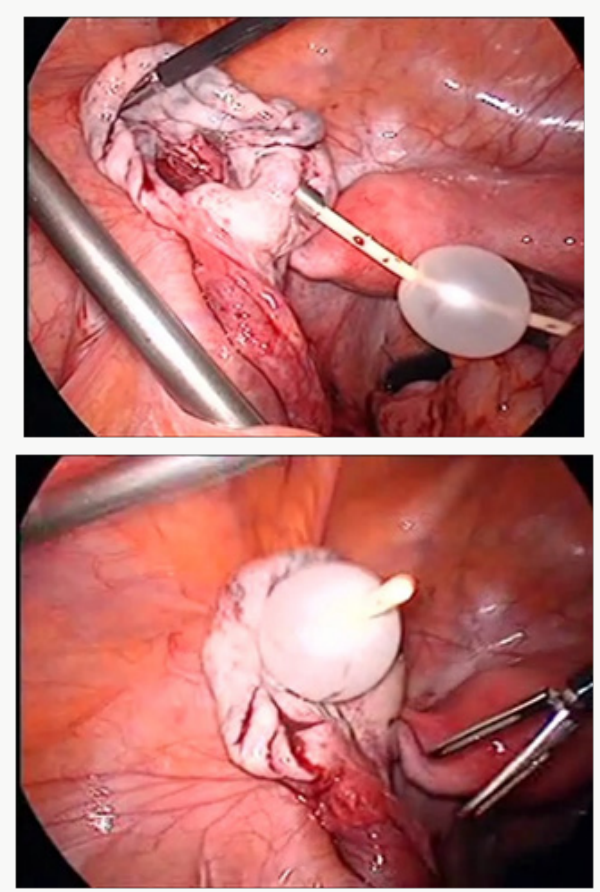

Figure 4: Compression and ventrosuspension with the Foley catheter. g. 6-8 hours after the operation (stabilization of clots resulting from natural hemostasis in the ovary) the slippery filament or Foley catheter was easily removed.

h. Ultrasonic monitoring of the ovarian migration after temporary ventro suspension to its usual site of localization (in such a short period the ovary does not manage to fix itself to the peritoneum at the point of its temporary location) $[6,7]$.

112 operations on the ovary were performed with the application of this method: 65 - with fixation by the filament and 47 - with fixation by the Foley catheter. Prior to surgery and in the postoperative period, the main indicators characterizing the state of the ovarian reserve (AMH, FSH, LH, InB), the number of antral follicles and blood flow parameters were controlled. Patient monitoring continues. Long-term results are being analyzed. As a result, temporary compression hemostasis allows us to perform almost bloodless surgical intervention on the ovary without the use of aggressive coagulation and other physical (laser, ultrasound) effects on the follicular apparatus of the ovary $[8,9]$.

\section{References}

1. Ben Shian Huang, Peng Hui Wang, Hsiao Wen Tsai, The Fu Hsu, Ming Shyen Yen, et al. (2014) Single-port compared with conventional laparoscopic cystectomy for ovarial dermoid cysts. Taivanese Journal of Obstetrics \& Gynecology 53: 523-529.

2. Hye yon Cho, Sung Taek Park, Min Sun Kyung, Sung ho Park (2017) Assessment of ovarian reserve after hysterectomy: laparoscopic vs. non-laparoscopic surgery. EJOG (European Journal of Obstetrics \& Gynecology and Reproductive Biology 210: 54-57.

3. Zhang CH, Wu L, Li PQ (2016) Clinical study of the impact of ovarian reserve by different hemostasis methods in laparoscopic cystectomy for ovarian endometrioma. Taiwan J Obstet Gynecol 15(4): 507-511.

4. Kang JH, Kim YS, Lee SH, Kim WY (2015) Comparing of hemostatic sealants on ovarian reserve during laparoscopic ovarian cystectomy. Eur J Obstet Gynecol Reprod Biol 194: 64-67.

5. Asgari Z, Rouholamin S, Hosseini R, Sepidarkish M, Hafizi L, et al. (2015) Comparing ovarian reserve after laparoscopic excision of endometriotic cysts and hemostasis achieved either by bipolar coagulation or suturing: a randomized clinical trial. Arch Gynecol Obstet 293(5): 1015-1022.

6. Zaitoun M., Zaitoun M, El Behery M (2013) Comparing long-term impact on ovarian reserve between laparoscopic ovarian cystectomy and open laparotomy for ovarian endometrioma J Ovarian Res 6(1): 76.

7. Roman H, Pura I, Tarta O, Mokdad C, Auber M, et al. (2011) Vaporization of ovarian endometrioma using plasma energy: histologic findings of a pilot study. Fertil Steril 95(5): 1853-1856.

8. Song T, Kim WY, Lee KW, Kim KH (2015) Effect on ovarian reserve of hemostasis by bipolar coagulation versus suture during laparoendoscopic single-site cystectomy for ovarian endometriomas. J Minim Invasive Gynecol 22(3): 415-420.

9. Ata B, Turkgeldi E, Seyhan A, Urman B (2015) Effect of hemostatic method on ovarian reserve following laparoscopic endometrioma excision; comparison of suture, hemostatic sealant, and bipolar dessication. A systematic review and meta-analysis. J Minim Invasive Gynecol 22(3): 363-372. 
CC (P) This work is licensed under Creative

To Submit Your Article Click Here :

Submit Article

DOI: $10.32474 /$ RRHOAJ.2018.01.000120

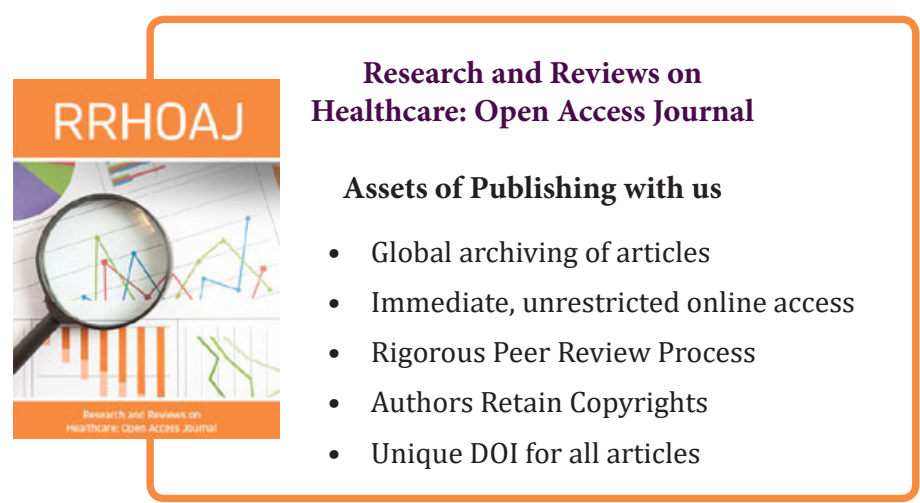

